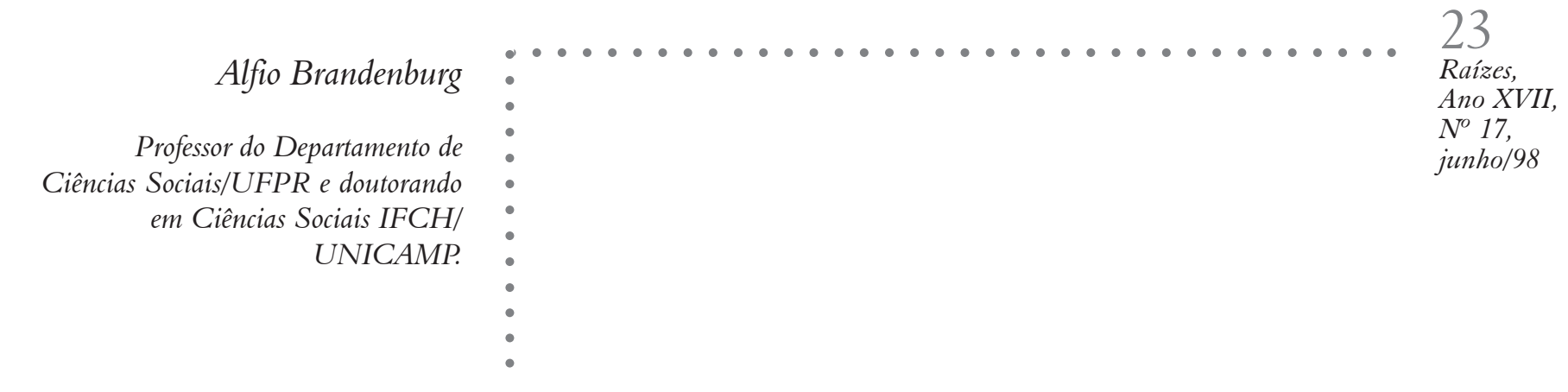

\title{
Agricultura Familiar e Produção Alternativa no Centro-oeste do Paraná ${ }^{1}$
}

\section{1 - Introdução}

Este texto trata das condições de reprodução da agricultura familiar e das condições para a realização de seus atores enquanto sujeitos sociais. Nesse sentido, os agricultores são considerados não apenas atores, mas também autores das condições sociais em que vivem. Tem-se como pressuposto que para "ser um agricultor familiar" há necessidade de recursos e instrumentais técnicos de realização econômica e de instituições sociais básicas de identificação social e diferenciação de outros grupos. Nesse sentido, a análise das condições de realização dos agricultores está agrupada em dois eixos básicos: a unidade de produção familiar e sua relação com o mercado, e as estruturas básicas de organização social e política dos agricultores.

\section{2 - O Local e os Atores Pes- quisados}

O estudo foi desenvolvido a partir de dados coletados junto aos agricultores orientados pela Fundação para o Desenvolvimento da Agricultura do Centro-Oeste do Paraná - RURECO. Esta organização é constituída por associações de agricultores dos municípios de Turvo, Pitanga, Nova Tebas, Pinhão, Laranjeiras do Sul, Nova Laranjeiras e Cantagalo. Em razão dos critérios adotados (continuidade de trabalho e mínimo de dois anos de atendimento), a pesquisa foi realizada nos municípios de Turvo, Nova Tebas, Pinhão e Laranjeiras do Sul.

Trata-se de uma região altamente heterogênea sob o ponto de vista da sua estrutura fundiária. Tradicionalmente, a região, que tem como polo de atração a cidade de
Guarapuava, foi constituída por latifundiários que exploravam a madeira e a pecuária (WESTPHALEN: 1968). Assim, em função do seu caráter de ocupação desenvolveu-se uma agricultura modernizada, especializada em trigo, soja e milho, e uma agricultura diversificada, cuja produção é realizada por pequenos agricultores familiares. Estes agricultores, salvo os caboclos que alí já residiam, são imigrantes de diversas origens étnicas, procedentes de vários locais. Como todas as correntes migratórias no Paraná partiram, normalmente, da periferia em direção ao centro, a região centro-oeste constitui uma das últimas a ser ocupada. Encontramos muitos agricultores que já não procediam de outros Estados, mas do próprio $\mathrm{Pa}-$ raná. Eles são descendentes de agricultores que se estabeleceram no Sudoeste/Oeste, ou daqueles da região tradicional (de Irati e Pru-

- ${ }^{1}$ Este texto constitui parte do projeto de pesquisa "ONGs e o Desenvolvimento da

- Agricultura: o caso RURECO”, que será apresentado como Tese, atendendo um dos

- requisitos do programa de doutorado em Ciências Sociais - IFCH/UNICAMP. 
dentópolis), ou ainda, do Norte do Estado. São de diversas etnias, conforme demonstrado na tabela 1 .

É significativo o número de caboclos ${ }^{2}$, entre os agricultores entrevistados, em todos os municípios. Entretanto, é no município de Pinhão, que os caboclos mais se concentram.

Também é notório no município de Nova Tebas, mais ao norte da região, agricultores descendentes de caboclos e italianos, não havendo praticamente represen- tantes das correntes migratórias vindos do sul.

Os dados confirmam ser a diversidade étnica a característica desta região, cujos primeiros ocupantes foram índios e caboclos, e cujos últimos foram imigrantes que vieram expulsos de outras regiões, pelo processo de modernização. Muitos dos que se estabeleceram nesses municípios, só foram tardiamente atingidos pelos serviços de assistência que possibilitaram sua integração na economia de mercado, e na sociedade.

Tabela 1 - Origem étnica dos agricultores entrevistados, segundo os municípios (\%)

\begin{tabular}{|l|c|c|c|c|c|}
\hline \multicolumn{1}{|c|}{ Município } & Caboclo & Polonês & Alemão & Italianos & Outros* $^{*}$ \\
\hline Turvo & 7 & 1 & 6 & 5 & 2 \\
\hline Nova Tebas & 10 & & & 3 & 1 \\
\hline Pinhão & 18 & 5 & 9 & 4 & 1 \\
\hline Laranjeiras do Sul & 10 & 2 & 7 & 7 & 2 \\
\hline
\end{tabular}

Fonte: pesquisa de campo 95/96

* Francês, Ucraniano, Uruguaio, Árabe

Tabela 2 - Posse da terra, segundo agricultores orientados (\%)

\begin{tabular}{|c|c|c|c|c|c|}
\hline & Proprietário & Arrendatário & Parceiro & Ocupante & Posseiro \\
\hline RURECO & 82 & 6 & 2 & 2 & 16 \\
\hline OUTROS & 92 & 12 & 2 & & \\
\hline
\end{tabular}

Fonte: pesquisa de campo 95/96

PARTE I A AGRICULTURA FAMILIAR ENTRE OS NOVOS DESA. FIOS DO MUNDO MODERNO

\section{3 - A Unidade Familiar de Produção}

\subsection{A terra e o trabalho}

Condição primeira da existência da produção familiar, a posse da terra é central tanto para a constituição da identidade de agricultor como para organizar tecnicamente a produção. A situação em relação à posse vai definir uma estratégia de sobrevivência do agricultor e determinar as suas condições de reprodutibilidade. No caso da região estudada, os agricultores, em sua maioria (82\%), detém o domínio da posse da terra, isto é, são proprietários, como é demonstrado na tabela 2 .

O tamanho da área em que trabalham situa-se entre 2 a 42 alqueires para $96 \%$ dos agricultores, sendo que $72 \%$ trabalham em área menor que 12 alqueires, conforme mostra a tabela 3 .

O agricultor entrevistado, mais do que proprietário de uma área de terra, é um trabalhador: ou melhor é um proprietário que trabalha com a família (WANDERLEY: 1989). Neste sentido, todos os agricultores que se intitulam proprietários participam das atividades agrícolas, dirigindo e executando tarefas, ou atuando com a

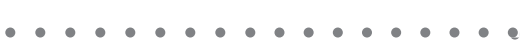

- ${ }^{2}$ Considerou-se como caboclos aqueles que se identificaram como tal, ou aqueles que

- mesmo lembrando ser descendentes de imigrantes, não conheceram nenhum costume

- e jamais praticaram sua língua. Vivem portanto a cultura cabocla. Os que se dizem de

- origem estrangeira, são descendentes de segunda ou terceira geração, ou seja, de avós

- ou bisavós estrangeiros. São agricultores que assimilaram a cultura cabocla mas que

- de alguma forma ainda lembram ou praticam costumes de seus antecedentes. 
seguinte composição da força de trabalho: família, exclusivamente $=17 \%$; família mais vizinhos/parentes na forma de troca de dias de trabalho $=39 \%$; família mais mão-de-obra contratada $=28 \%$; família, mais troca de dias, mais mão-de-obra contratada $=15 \%$. (tabela 4).

Não sendo suficiente a mão-deobra da família, os agricultores recorrem primeiro à permuta de dias de serviço e após a contratação, que contudo é realizada apenas em época de pico de trabalho e por isso recorrem mais à mãode-obra temporária.

Mas se, por um lado, a mão de obra torna-se escassa, pelo menos em determinados períodos, para grande parte dos produtores, por outro, ela constitui um excesso ou não é suficientemente remunerada para poder reproduzir-se, ou manter os membros do núcleo organizador do trabalho, com os recursos existentes na unidade produtiva. Recorre-se então à venda da força de trabalho, seja em caráter permanente ou temporário. Relevante neste caso, é que a procura de trabalho, fora da propriedade familiar, é sempre em tempo parcial. Isto por que esses "trabalhadores proprietários", antes de serem assalariados se intitulam agricultores e nesse sentido o assalariamento constitui um recurso, embora indispensável, complementar. Mesmo aqueles que têm na agricultura apenas uma atividade de subsistência (no sentido de ser orientada mais para consumo próprio), mas que sobrevivem graças ao salário de empregado, identificam-se como agricultores, na esperança de um dia poderem reverter sua situação. $\mathrm{O}$ trabalho complementar, então, não modifica sua condição de agricultor (SANTOS: 1978).

Entre os entrevistados, os agricultores sem orientação $(57,1 \%)$

Tabela 3 - Número de estabelecimentos por estrato de área, segundo os agricultores orientados (\%)

cultores sem orientação $(57,1 \%)$
Tabela 3 - Número de estabelecimentos por estrato de área,
segundo os agricultores orientados $(\%)$
\begin{tabular}{|c|c|c|c|}
\hline RURECO & \multicolumn{2}{c|}{ OUTROS } \\
\hline Tamanho em alq. & Número & Tamanho em alq. & Número \\
\hline $2,0-12$ & 72 & $1,5-20$ & 78 \\
\hline $12-22$ & 16 & $20-40$ & 12 \\
\hline $22-32$ & 4 & $40-60$ & 2 \\
\hline $32-42$ & 4 & $60-80$ & 4 \\
\hline+ de 42 & 4 & + de 80 & 4 \\
\hline
\end{tabular}

Fonte: pesquisa de campo 95/96

Tabela 4 - Natureza da mão-de-obra utilizadas nas unidades produtivas, conforme os agricultores orientados $(\%)$

\begin{tabular}{|l|c|c|c|c|c|}
\hline & $\begin{array}{c}\text { Sem } \\
\text { resposta }\end{array}$ & Familiar & $\begin{array}{c}\text { Familiar+ } \\
\text { troca dias }\end{array}$ & $\begin{array}{c}\text { Familiar+ } \\
\text { contratada }\end{array}$ & $\begin{array}{c}\text { Familiar+ } \\
\text { troca + } \\
\text { contratação }\end{array}$ \\
\hline S/ORIENT. & 7,1 & 21,4 & 35,7 & 35,7 & \\
\hline RURECO & & 12,0 & 46,0 & 22,0 & 20,0 \\
\hline TOTAL & 1 & 17,0 & 39,0 & 28,0 & 15,0 \\
\hline
\end{tabular}

Fonte: pesquisa de campo 95/96

Tabela 5 - Famílias com trabalho complementar e destino da renda, segundo categorias orientadas (\%)

\begin{tabular}{|l|c|c|c|c|}
\hline & Manutenção & $\begin{array}{c}\text { Investimento } \\
\text { próprio }\end{array}$ & $\begin{array}{c}\text { Manutençãoe e } \\
\text { Investimento }\end{array}$ & Total \\
\hline RURECO & 18,0 & 8,0 & 12,0 & 38,0 \\
\hline OUTROS & 30,0 & 2,0 & 10,0 & 42,0 \\
\hline SEM ORIENTAÇÃO & 42,9 & 7,1 & 7,1 & 57,1 \\
\hline
\end{tabular}

Fonte: pesquisa de campo 95/96 constituem justamente a categoria dos que mais buscam recursos atividades fora da propriedaconsiderável o percentulat da les atendidos por outras entidades (praticamente todos acima de $30 \%)$, conforme a tabela 5 . 
A tabela 5 chama a atenção para o fato de que entre os agricultores não orientados, 42,9\% complementam a renda fora da propriedade familiar visando exclusivamente a manutenção da família, isto é, sem investir na propriedade, denotando constituir a categoria mais empobrecida ou com dificuldades de se manter, apenas através da sua própria produção agrícola. Fica claro nesta situação a importância dos serviços de orientação prestados por estas instituições, sem os quais, pode se afirmar, o grau de agravamento da situação social e econômica destes agricultores e, conseqüentemente do processo de migração, certamente seria maior.

Contudo, para a maioria dos entrevistados, buscar recursos financeiros externos à unidade de produção familiar não significa privilegiar financeiramente "quem trabalha fora", na medida em que se está vinculado a um grupo que organiza a produção familiarmente. Salvo aqueles já casados, todos os elementos da família que trabalham em outros estabelecimentos, ou que auferem renda proveniente de fontes externas revertem seus ganhos para o caixa familiar. Isto significa dizer que, tanto para os atendidos pela RURECO como para os demais, a renda obtida por qualquer componente da família é “indivisível” (tabela 6).

O esforço para conseguir se manter enquanto categoria, refle-

Tabela 6 - Renda familiar e remuneração da mão-de-obra, segundo agricultores orientados (\%)

\begin{tabular}{|c|c|c|c|}
\hline & Indivisivel & $\begin{array}{c}\text { Remunera } \\
\text { casados }\end{array}$ & $\begin{array}{c}\text { Divide } \\
\text { com filhos }\end{array}$ \\
\hline RURECO & 88 & 10 & 2 \\
\hline OUTROS & 82 & 12 & 2 \\
\hline
\end{tabular}

Fonte: pesquisa de campo 95/96

Tabela 7 - Grau de autonomia do agricultor familiar, em relação a outras categorias de trabalhadores, segundo orientações prestadas

te-se de forma nítida na jornada de trabalho, que, para $47 \%$ dos agricultores entrevistados, é cada vez maior. Interrogados sobre quantas horas dispensa diariamente ao trabalho, uma resposta recorrente expressa o quanto trabalha:

"Agricultor começa a trabalhar quando amanhece e só para quando anoitece".

Mas, se trabalhar mais parece ser a ordem reinante entre os entrevistados, o "mais trabalho" parece estar relacionado a uma outra questão, muito cara, contudo inegociável na percepção dos agricultores: a autonomia ou liberdade que a natureza de sua atividade oferece. Conforme a tabela 7 abaixo, na visão de praticamente a metade de ambas as categorias entrevistadas, os agricultores trabalham mais, mas têm mais autonomia que em outras atividades. Se somarmos os itens, "tem mais que outras" e "trabalha mais, mas tem mais autonomia" o percentual relativo a mais autonomia chega aos $80 \%$.

Na perspectiva do agricultor, "ser autônomo" "é não viver abaixo de ordem" (ent. 05) "é não ter obrigação com o patrão" e poder até ter a liberdade de "se quiser parar para descansar" (entr. 75). A autonomia da qual se trata, referese a um controle interno sobre a produção, sobre a organização do trabalho e sobre os processos de decisão, indicando que nem tudo é determinado exteriormente conforme já foi demonstrado por WAN- 

DERLEY (1989) e PAULILO
(1990).

Contudo, a preservação disto que o camponês de ontem prezava, e que o agricultor familiar moderno ainda preza nos dias de hoje, tem um preço: o trabalho sofrido, ou "penoso". A penosidade é maior para aqueles que, não tendo condições de adquirir modernos instrumentos de trabalho, para melhorar sua rentabilidade, obrigam-se a despender mais energia física, a trabalhar mais intensamente. Como diz um agricultor:

\footnotetext{
"a máquina diminui trabalho ...(que) fica mais leviano. Com a crise o trabalho fica mais pesado" (entr. $\mathrm{n}^{\circ} 71$ ).
}

\subsection{A produção}

As unidades familiares estão organizadas em termos de uma produção diversificada, ao contrário da lógica produtivista que maximiza a racionalidade econômica, mediante sistemas especializados. As atividades dos agricultores na região são praticadas considerando as seguintes culturas e criações: milho, feijão, arroz, erva mate, soja, hortaliças e frutas, fumo, gado (leite e corte) aves, bicho da seda, abelha, suínos e ovelha. Como se sabe, hortaliças e frutíferas compreendem uma grande diversidade de espécies, mas foram englobadas em torno de um tipo de exploração pelo fato de serem cultivados, em geral, para consumo próprio.

Entre os produtos cultivados, a erva mate constitui uma exploração tipicamente regional. Ela é explorada por $48,3 \%$ dos produtores sendo a maioria de origem cabocla.

A atividade carbonífera constitui, entre as fontes de renda, a única exploração não agrícola.. Assim, mesmo os agricultores que vendem sua força de trabalho, sobrevivem de atividades agrícolas.

A diversidade de produtos cultivados vale tanto para os atendidos pela RURECO como para outros produtores, conforme a tabela 8 .

Embora entre os orientados pela rede RURECO haja uma ligeira variação de número de unidades com maior grau de diversidade, para mais, também os outros agricultores diversificam sua produção.

Tabela 8 - Unidades de produção, conforme o número de explorações agropecuárias, segundo agricultores atendidos (\%)

\begin{tabular}{|l|c|c|c|c|c|c|c|c|c|c|c|c|c|}
\hline & $\mathbf{1}$ & $\mathbf{2}$ & $\mathbf{3}$ & $\mathbf{4}$ & $\mathbf{5}$ & $\mathbf{6}$ & $\mathbf{7}$ & $\mathbf{8}$ & $\mathbf{9}$ & $\mathbf{1 0}$ & $\mathbf{1 1}$ & $\mathbf{1 2}$ & $\mathbf{1 3}$ \\
\hline RURECO & & & & & & 8 & $\mathbf{8}$ & 24 & 26 & 18 & 12 & 2 & 2 \\
\hline OUTROS & & & & $\mathbf{8}$ & 6 & 4 & 26 & 26 & 18 & 8 & 4 & & \\
\hline
\end{tabular}

Fonte: pesquisa de campo 95/96

Observando-se a tabela 13 constata-se que o menor número de explorações por unidade/RURECO é seis, enquanto o de outras unidades é quatro. Mas, considerando-se que o maior do percentual de agricultores está entre 8 e 10 alternativas para RURECO, e, 7 e 9 alternativas para OUTRAS categorias, verifica-se que ambas as categorias diversificam sua produção.

A diversificação da exploração agrícola não é, então, um atributo exclusivo dos atendidos pela RURECO, mas de todos os agricultores familiares da região. Isto pode ser interpretado como fenômeno de uma crise ou característica de um determinado tipo de organização de produção? Do ponto de vista econômico, somente uma especialização em torno de atividades específicas daria condições para os agricultores competirem no mercado. Nestes termos, o modelo dominante preconiza a especialização e o aprimoramento técnico tendo em vista a necessidade de produzir a baixo custo e com qualidade tecnicamente competitiva. Daí a lógica de se produzir cada vez mais barato, para se poder ganhar mais. Como porém, a agricultura não está suficientemente modernizada na região, - sob o ponto de vista de sua "base técnica" - pelo menos em alguns setores (KAGEYAMA: 1985), certos produtos, não teriam condições de competir, seja por falta de condições técnicas aprimoradas, ou pelos limites das escalas de produção, impostos pelo tamanho da propriedade, ou ainda pela falta de 
infraestrutura; daí a necessidade de manter diversificada a produção e com o recurso da mão-de-obra familiar, que, por sua vez, não é remunerada individualmente.

Por outro lado, a manutenção de uma produção diversificada pode ser atribuída à família, uma vez que

"diversificar a produção pode não ser a extensão do que é economicamente vantajoso, mas do que é socialmente desejável e possivel no seio do grupo". (DARRÉ, citado por LAGRAVE: 1988, p. 107).

A estratégia de reprodução através da diversidade visa não somente a segurança econômica, mas também a social e simbólica. Nesse sentido, a explicação da diversidade parece não estar relacionada a uma causa específica, mas associada a fatores diversos resultantes de um processo de ajustamento da unidade produtiva, que é operada pela família. Este ajustamento, do ponto de vista ambiental ou ecológico, representa ainda, assegurar condições de reprodutibilidade social, na medida em que a diversidade significa estabilidade de um ecossistema. Embora não possa ser colocado como resultante de uma consciência ambiental, de grande parte dos agricultores entrevistados, a diversidade na agricultura familiar se coloca como uma questão relevante no momento em que o meio ambiente se coloca como uma "questão global" que atinge todas as categorias sociais.
Diversidade na produção parece também estar associado a lógicas diversas, na medida em que produzir para o consumo na propriedade e produzir para o mercado é orientado por objetivos distintos. Produzir para o mercado e ao mesmo tempo para o auto-abastecimento satisfaz as necessidades da família, mas não satisfaz uma produção exclusiva para o mercado ou exclusiva para o abastecimento familiar. Na sua reprodução, o sistema familiar aparece diversificado e especializado ao mesmo tempo. $\mathrm{Na}$ busca de um rendimento financeiro a família se especializa em torno de um ou mais produtos orientados ao mercado, seja através da produção integrada à AGROINDÚSTRIA, COOPERATIVA ou ASSOCIAÇÕES, seja através da integração a circuitos comerciais, realizadas por intermediário. Isto ocorre inclusive com agricultores adeptos da agroecologia:

"o agricultor precisa assegurar renda fixa e diversificar a produção" (entr. $\mathrm{n}^{\circ}$. 11).

A exploração que aufere mais

\begin{tabular}{|l|c|c|c|c|c|c|}
\hline Orientação & Manual & $\begin{array}{c}\text { Tração } \\
\text { animal }\end{array}$ & Mecanizado & $\begin{array}{c}\text { Manual + } \\
\text { Traç. Animal }\end{array}$ & $\begin{array}{c}\text { Man.+ T.A. } \\
+ \text { Mecanizado }\end{array}$ & $\begin{array}{c}\text { Traç. Animal } \\
+ \text { Mecanizado }\end{array}$ \\
\hline Sem Or. & 21,4 & & 7,1 & 50,0 & 21,4 & \\
\hline RURECO & 6,0 & 6,0 & 4,0 & 64,0 & 18,0 & 2,0 \\
\hline EMATER & 2,0 & 11,6 & 14,0 & 41,9 & 23,3 & 4,7 \\
\hline Agro-Ind. & 4,8 & 9,5 & 9,5 & 47,6 & 19,0 & 9,5 \\
\hline Cooper. & & 7,1 & 39,3 & 28,6 & 14,3 & 7,1 \\
\hline COAGRI & & & & 37,5 & 62,5 & \\
\hline
\end{tabular}

renda é aquela a que o agricultor mais se dedica no que tange ao seu aperfeiçoamento técnico, muitas vezes por força de um contrato de produção, como no caso da agroindústria ou mesmo da cooperativa. Neste caso, a técnica convencional atinge "uma” exploração agrícola, e não "todos” os produtos cultivados. É por isso que não se pode dizer que a unidade de produção familiar está modernizada tecnicamente. As técnicas convencionais atingem setores $\mathrm{da}$ produção e não conseguem homogeneizar a unidade familiar, conforme já ficou demonstrado (BRANDENBURG e FERREIRA:1995; PAULILO: 1990; WANDERLEY: 1990). A heterogeneidade dos sistemas técnicos de produção é constatada nos índices da tabela 9.

São os sistemas mistos que predominam entre os agricultores entrevistados, mesmo entre os que por hipótese estariam mais diretamente sujeitos à utilização de tecnologia convencional, como os integrados à agroindústria, cooperativas e mesmo orientados pela EMATER. Dos agricultores da rede RURE$\mathrm{CO}, 64 \%$ operam em sistemas cuja 
força de tração é animal e cujas atividades são executadas manualmente. Esse índice está relacionado com os agricultores que valorizam positivamente os equipamentos poupadores de capital, os recursos energéticos e a mão-deobra existentes na propriedade.

Do lado das técnicas poupadoras de mão-de-obra, os agricultores das cooperativas constituem aqueles que apresentam maior índice de força de tração exclusivamente motomecanizada: $39,3 \%$. Ao mesmo tempo entre esses agricultores estão também aqueles que apresentam menor índice de sistemas com tração animal e manual. Se somarmos os que se mecanizaram, conjugando tração animal com força manual, verificaremos que serão os agricultores vinculados à COAGRI os mais modernizados tecnicamente, ou seja $62,5 \%$ dos entrevistados, seguidos da cooperativa $(60,7 \%$,$) EMATER$ (41\%) e Agroindústria (38\%). Ressalta-se, porém, que os dados referentes aos agricultores/Coagri são relativos à aquisição de máquinas em grupo e não por unidade produtiva.

Através da tabela 14, pode-se ilustrar dois casos típicos de orientações diferentes. De um lado, os agricultores/Rureco previlegiando equipamentos de tração animal e força de trabalho manual (64\%); de outro, entre os agricultores/ Cooperativas, o maior índice dos que privilegiam exclusivamente máquinas e equipamentos motorizados $(39,3 \%)$, embora no seu conjunto ainda predominem os sistemas mistos de forças de tração.

A diversidade de padrões técnicos parece também orientar as práticas agrícolas e o uso de insumos. É comum entre agricultores a utilização de insumos industriais e recursos naturais processados nas unidades produtivas. Assim, por exemplo, usam-se os agroquímicos adubos, inseticidas, herbicidas, e ao mesmo tempo, adubação verde, esterco e práticas de manejo de solos, embora as categorias não atendidas pela rede RURECO, tendam a utilizar mais insumos industriais. A tabela 10 nos dá essa indicação.

Um maior índice de agricultores que utilizam práticas orgânicas de agricultura, que poderiam ser chamadas de ecológicas, é encontrado entre os orientados pela RURECO, quando comparado com as outras categorias. Entre as práticas adubação verde, uso de esterco, rotação de cultura, plantio em nível e culturas consorcia- das, somente o plantio em nível é praticado por uma percentagem maior de outros agricultores. A prática de controle biológico, embora considerada de manejo ecológico, normalmente é empregada na soja, que não é cultivada pelos orientados/RURECO.

Adubação química (calcário e fertilizantes) e pesticidas (inseticidas e herbicidas) são insumos industriais, utilizados por um número maior de outros agricultores, embora o calcário seja um insumo, segundo os técnicos, necessário mesmo para a agricultura orgânica. Como era de se esperar, o índice maior está sempre entre as categorias orientadas, por órgãos como EMATER, AGROINDÚSTRIA, COOPERATIVAS E COAGRI. Com relação aos insumos industriais, ainda é preciso salientar que os agricultores da rede RURE$\mathrm{CO}$, quando indagados sobre o seu uso, muitas vezes respondiam que os utilizavam, mas pouco, demonstrando praticar uma agricultura de insumos industriais reduzidos. 
É preciso concluir então, segundo a leitura da tabela acima, que o impacto para uma política de ação que preconiza uma agricultura de práticas ecológicas, é maior entre os agricultores orientados pela RURECO.

\subsection{Investimentos}

Apesar de poucos agricultores terem realizado investimentos nos últimos três anos, o maior percentual daqueles que fizeram, principalmente crédito de custeio ${ }^{3}$, situa-se entre os agricultores orientados pela RURECO, conforme a tabela 11 .

O baixo investimento realizado em benfeitorias, máquinas e equipamentos agrícolas, conforme a tabela 11, está relacionado a um período de crise conjuntural na agricultura, que vem se agravando nos últimos anos, conforme a visão dos agricultores. Existe uma orientação, comum entre os agricultores entrevistados, de preferencialmente utilizar recursos próprios nos investimentos produtivos, e evitar ao máximo o uso de recursos oriundos de empréstimos bancários. Esta posição está baseada na experiência de muitos agricultores, que foram obrigados a vender seu "patrimônio mais caro", para pagar suas dívidas junto ao banco: a terra. Há uma certa consciência de

Tabela 11 - Natureza de investimentos realizados nos anos 93/94/95, segundo categorias de agricultores e origem dos recursos $(\%)$

\begin{tabular}{|l|c|c|r|r|r|r|r|r|}
\hline & \multirow{2}{*}{ RURECO } & \multirow{2}{*}{ OUTROS } & \multicolumn{3}{|c|}{ RURECO } & \multicolumn{3}{c|}{ OUTROS } \\
\cline { 4 - 10 } & & & $\mathbf{1}$ & $\mathbf{2}^{*}$ & $\mathbf{3}^{* *}$ & $\mathbf{1}$ & $\mathbf{2}^{*}$ & $\mathbf{3}^{* *}$ \\
\hline Benfeitorias & 18,0 & 12,0 & 6 & 8 & 4 & 4 & 8 & \\
\hline Máq. e equipamentos & 10,0 & 10,0 & & 8 & 2 & & 10 & \\
\hline Custeio & 38,0 & 28,0 & 2 & 14 & 22 & 4 & 12 & 12 \\
\hline
\end{tabular}

Fonte: pesquisa de campo 95/96

1 - recursos próprios; $2^{*}-$ crédito; $3^{* *}$ - recursos próprios + crédito

que os juros bancários são excessivamente altos e difíceis de serem pagos com a renda proveniente da agricultura. Como relata um agricultor vindo do oeste do Paraná:

\footnotetext{
"o financiamento que fizemos não deu para cobrir .(com a produção).Tivemos que vender terra para pagar o trator. Só trabalhava para pagar juros..." (entr. $\mathrm{n}^{\mathrm{o}}$. 46).
}

Há casos em que os agricultores foram obrigados a vender todo o patrimônio que possuíam em outras regiões, para saldar suas dívidas. Restou-lhes, com o que sobrou, recomeçar comprando terras mais baratas e menos férteis, na região centro-oeste. Esta experiência vivida por agricultores, principalmente aqueles que já passaram pela modernização técnica, serve de lição, mesmo para aqueles que não a vivenciaram. Pela situação analisada, conclui-se que o não endividamento é, então, uma posição relacionada com uma certa racionalidade econômica, onde o empréstimo é realizado apenas quando não se consegue poupar recursos (NEVES: 1981).

\section{4 - A Relação com o Mercado}

Conforme a exposição anterior, os produtos orientados para o mercado são os mais privilegiados em relação à melhoria das condições técnicas de cultivo. Isto significa que a organização técnica da produção está diretamente relacionada com o grau de integração da unidade produtiva no mercado. Conforme demonstrado na tabela 17 , os agricultores da rede RURECO cultivam arroz e hortaliças principalmente para autoconsumo, e orientam milho e feijão, simultaneamente, para o mercado e consumo. Em relação ao grupo das criações, ave é um produto típico de consumo familiar, sendo a produção de leite, suínos e mel também comercializada.
- ${ }^{3}$ A utilização do crédito de custeio, deve-se a um programa especial existente no

- Paraná, até 1994, que previa a possibilidade do empréstimo ser pago em volume de

- produção. Assim, por exemplo, o valor de um plano de financiamento era calculado

- em sacas de milho correspondente na época do financiamento. Na data do

- vencimento, o pagamento poderia ser feito mediante o mesmo número de sacas de - milho, independente do seu preço no mercado. 
Entre os agricultores da rede RURECO, $54 \%$ e $32 \%$ dos produtores de milho e feijão, respectivamente, comercializam seus produtos através de suas associações ou cooperativas. $10 \%$ de produtores de milho e $20 \%$ de produtores de feijão, ainda estão sob controle do capital comercial, ou intermediários. Estes mesmos agentes de comercialização controlam também $32 \%$ e $26 \%$ dos outros produtores de milho e feijão, respectivamente. A erva mate é um produto fornecido a beneficiadores locais, assim como hortaliças, quando vendidas, são oferecidas ao comércio local ou diretamente para consumidores. A soja, cultivado por apenas $4 \%$ dos agricultores/RURE$\mathrm{CO}$, é toda comercializada pela rede de cooperativas. O fumo é o único produto praticamente produzido apenas para a agroindústria. A produção de suínos, embora também integrada, é em grande parte destinada ao autoconsumo, conforme a tabela 13 .

Leite e mel, conforme a tabela 13 , tem comercialização organizada através de cooperativas ou associações de $18 \%$ e $42 \%$ dos agricultores/RURECO.

Quanto ao leite, observou-se

Tabela 12 - Número de agricultores por cultura e destino da produção (\%)

\begin{tabular}{|l|c|c|c|c|c|c|c|c|}
\hline \multirow{2}{*}{ Produtos } & \multicolumn{2}{c|}{ Autoconsumo } & \multicolumn{2}{c|}{ Cooper./Assoc. } & \multicolumn{2}{c|}{ Agroindústria } & \multicolumn{2}{c|}{ Interm./outros } \\
\cline { 2 - 10 } & RURECO & Outros & RURECO & Outros & RURECO & Outros & RURECO & Outros \\
\hline Milho & 42 & 68 & 54 & 40 & & & 10 & 32 \\
\hline Feijão & 44 & 66 & 32 & 26 & & & 20 & 26 \\
\hline Arroz & 66 & 50 & 2 & & & & & 2 \\
\hline Erva Mate & & & & 2 & & 2 & 30 & 10 \\
\hline Soja & & & 4 & 16 & & & & \\
\hline Hort. e Frutas & 92 & 84 & 2 & & & 2 & 14 & 4 \\
\hline Fumo & & & 2 & 2 & 8 & 16 & 6 & \\
\hline
\end{tabular}

Fonte: pesquisa de campo 95/96

Tabela 13 - Número de agricultores por criações e destino da produção

\begin{tabular}{|l|r|r|r|r|r|r|r|r|}
\hline \multirow{2}{*}{ Produtos } & \multicolumn{2}{|c|}{ Autoconsumo } & Cooper./Assoc. & \multicolumn{2}{|c|}{ Agroindústria } & \multicolumn{2}{|c|}{ Interm./outros } \\
\cline { 2 - 9 } & RURECO & Outros & RURECO & Outros & RURECO & Outros & RURECO & Outros \\
\hline Leite & 96,0 & 82,0 & 18,0 & 10,0 & 12,0 & 6,0 & 16,0 & 20,0 \\
\hline Aves & 86,0 & 88,0 & & & & & & 2,0 \\
\hline Bicho da Seda & & & & & 2,0 & & & \\
\hline Mel & 18,0 & 2,0 & 42,0 & 4,0 & & & 4,0 & \\
\hline Suínos & 72,0 & 68,0 & & 2,0 & 4,0 & 8,0 & 6,0 & 8,0 \\
\hline Ovelhas & 16,0 & 14,0 & & & & & 6,0 & 2,0 \\
\hline
\end{tabular}

Fonte: pesquisa de campo 95/96 um grande interesse em ampliar a atividade, conforme se mostrará na seqüência, denotando também constituir um produto com comercialização pouco organizada para $16 \%$ de produtores. Ele é vendido, em grande parte, "in natura" ou na forma de derivados, principalmente queijo, diretamente para o comércio ou para consumidores locais. Em função de não haver uma demanda de consumo que possa absorver toda a produção, no âmbito dos municípios, normalmente ocorrem sobras que desestimulam o produtor. Deve-se observar que a localização das propriedades, muitas vezes, dificulta o escoamento do leite em função das más condições das estradas que dão acesso à propriedade. Além do que, falta uma melhor organização, tanto sob o ponto de vista técnico-organizativo, quanto do escoamento da produção.

Da leitura das tabelas 12 e 13, conclui-se que a comercialização da produção é controlada por diversos tipos de agentes. De um lado, não existe um agente que centralize a comercialização dos produtos, nem dos mais relevantes sob o ponto de vista do mercado; de outro, a relação dos agricultores com o mercado se realiza mediante vários atores e não apenas através de um, e se faz por meio de determinados produtos, e não pela totalidade do que se produz.

No caso da produção integrada à agroindústria, a relação contratual não se realiza através da unidade produtiva, mas de um ou dois produtos cultivados. Daí não FAMILIAR ENTRE OS NOVOS DESAFIOS DO MUNDO MODERNO 
se poder afirmar que a produção agrícola é controlada, e muito menos determinada unilateralmente por processos industriais. Impõe-se, isto sim, através da relação contratual, um padrão convencional de produção em torno do produto que é objeto do contrato, mas isto não significa que este padrão técnico se generaliza para todo o sistema produtivo. Os agricultores, principalmente os envolvidos com uma técnica "alternativa", dispensam tratamento técnico especial para a cultura contratualizada, sob a supervisão do técnico. As outras culturas são exploradas sob padrões tecnológicos diversos.

\section{5 - Organização Social e Política}

É na sede do que os agricultores chamam comunidade que encontramos as estruturas físicas, do comércio ou de instituições sociais como igreja, escola, lazer, em torno das quais se organizam a vida social de um núcleo ou grupo de agricultores, que na região normalmente habitam de forma dispersa. A comunidade, então, corresponde ao que Maria Isaura denominou bairro rural ou "grupo de vizinhança".

"O sitiante brasileiro habita em suas terras; as casas de uma zona de sítios estão dispersas em torno de pequeno núcleo central, constituído por capela, vendinha, duas ou três habitações, que formam como que a "capital" de um gru- po de vizinhança” (QUEIROZ: 1973 p. 50).

O núcleo comunitário, ou comunidade, é o local onde encontramos uma infra-estrutura social necessária à reprodução social dos grupos. Há sempre necessidade de um "mínimo" de instituições "sociais" para se promover o processo de socialização. Entre elas destacamos a Igreja, a Escola e o Lazer.

A noção de "mínimo social”, corresponde a uma unidade mínima

"por excelência da sociabilidade... Aquém dele, não há vida social estável, e sim o fenômeno ocasional do morador isolado, que tende a superar este estado, ou cair em anomia; além dele há agrupamentos, relações mais seguidas com o mundo exterior, características duma sociabilidade mais rica"(CANDIDO: 1975 p. 74).

Apenas 12\% dos agricultores entrevistados vivem em condições que parecem ultrapassar os mínimos sociais, e $16 \%$ dos agricultores/ RURECO e $10 \%$ dos demais vivem em condições de sociabilidade que poderiam ser considerados como precárias, uma vez que convivem apenas ou em torno da escola, ou da igreja, ou do lazer (Tabela 14).

A comunidade é também o local por excelência da prática da solidariedade (CANDIDO: 1975), ou local a que se pertence (FRANCO: 1992).

A solidariedade é exercitada na forma de troca de dias de serviços na organização do trabalho por $39 \%$ dos trabalhadores entrevistados. O mutirão, no sentido de envolver a comunidade mais ampla, constitui uma prática usada apenas para a construção de obras comunitárias, como Igreja, reformas na Escola, ou até infraestrutura de lazer.

O espaço da comunidade é um espaço social, onde se definem as condições econômicas e sociais da
Tabela 14 - Agricultores e Instituições comunitárias, segundo categorias orientadas (\%)

\begin{tabular}{|l|c|c|}
\hline & RURECO & OUTROS \\
\hline Igreja & 10 & \\
\hline Escola & 2 & \\
\hline Lazer & 4 & 6 \\
\hline Igreja e Escola & 18 & 14 \\
\hline Igreja/Escola/Lazer & 38 & 46 \\
\hline Igreja/Escola/Lazer/Posto Saúde & 18 & 28 \\
\hline Igreja/Escola/Lazer/Posto Saúde/Telefone & 8 & 4 \\
\hline
\end{tabular}

Fonte: pesquisa de campo 95/96 
produção e reprodução e a partir do qual se constrói uma identidade sócio-cultural e se organizam as bases de uma representação política dos agricultores.

Os elementos estruturantes da vida comunitária correspondem a experiências coletivas que tem raízes no passado de lutas, de organização de movimentos, como referidos no capítulo três, mas que são recriados em função da necessidade histórica dos atores se realizarem enquanto "sujeitos sociais”. E é nesta perspectiva que um mesmo agricultor participa de instituições que correspondem a várias dimensões de sua realização.

\subsection{Organizações comunitárias}

A participação de $70 \%$ e $72 \%$ dos agricultores (tabela 15), equilibrada entre ambos os grupos, em organizações do tipo comunitário (religioso, recreativo e cultural) revela o significado da realização sócio cultural em instituições, que se situam mais próximas, e que se incluem no que chamamos grupos de referência, a partir dos quais os agricultores constróem sua iden- tidade sócio-cultural e as bases de sua representação política. Esses grupos normalmente estão ligados a instituições, que promovem a integração social e encurtam distâncias sociais entre grupos. São grupos ligados à Igreja, à realização de festas ou eventos religiosos, e à atividades de lazer. No grupo comunitário, entendido como o grupo social mais amplo da comunidade, a Igreja, sem dúvida, ainda exerce papel central. Ela atrai não somente fiéis de uma religião, mas congrega atividades culturais e sócio-recreativas. Assim em torno da Igreja estão o galpão de festas, o campo de futebol, a escola. Dificilmente encontramos uma comunidade sem Igreja. Sua ausência pode ser interpretada como sinal de uma comunidade desintegrada, ou em desintegração.

Estreitamente ligada à Igreja, a festa do padroeiro, a celebração de dias santos, e de tradições culturais nos fornecem indicações interessantes. Entre as tradições, a Festa do Divino e a Dança de São Gonçalo são lembradas por famílias, principalmente de comunidades caboclas. Em outras comunidades, onde já ocorre uma certa

Tabela 15 - Participação em organismos sociais, conforme agricultores atendidos (\%)

\begin{tabular}{|c|c|c|c|c|c|c|c|c|c|c|}
\hline \multirow{2}{*}{$\begin{array}{c}\text { Grau de } \\
\text { Participação }\end{array}$} & \multicolumn{2}{|c|}{$\begin{array}{l}\text { Assoc. Relig. } \\
\text { Recre e Cultura }\end{array}$} & \multicolumn{2}{|c|}{$\begin{array}{l}\text { Associação } \\
\text { Comercial }\end{array}$} & \multicolumn{2}{|c|}{ Cooperativa } & \multicolumn{2}{|c|}{ Sindicato } & \multicolumn{2}{|c|}{$\begin{array}{l}\text { Partido } \\
\text { Político }\end{array}$} \\
\hline & RURECO & OUTROS & RURECO & OUTROS & RURECO & OUTROS & RURECO & OUTROS & RURECO & OUTROS \\
\hline Sócio & 70 & 72 & 92 & 18 & 50 & 48 & 70 & 48 & 50 & 22 \\
\hline Reunião & 60 & 66 & 88 & 2 & 30 & 30 & 48 & 12 & 26 & 2 \\
\hline Evento & 48 & 48 & 20 & 4 & & 8 & 10 & 6 & 8 & \\
\hline Direção & 36 & 46 & 30 & & 8 & 10 & 20 & 6 & 12 & \\
\hline
\end{tabular}

miscigenação cultural, estas manifestações folclóricas são lembradas como fatos do passado. Nestas, estas formas de manifestações culturais foram substituídas por outras, de certa maneira modernizadas por conjuntos musicais que hoje ocupam o lugar dos dançarinos romeiros. Com a chegada de colonos, vindos de outro Estado ou mesmo de outras regiões do Estado, houve uma certa alteração na composição orgânica da comunidade. Os costumes e práticas culturais do imigrante fizeram dele um estranho para os caboclos que, recolhendo-se nas suas tradições, não conseguiram passá-las para o imigrante. Vivendo de forma dispersa, o caboclo posseiro muitas vezes se retirava gradualmente, sendo encurralado pelos imigrantes que reforçados pelos hábitos de sua colônia conseguiram se impor de tal forma na região a ponto de fazer surgir uma nova comunidade, no sentido da prática de outras tradições. Assim, é possível encontrar comunidades de agricultores pertencentes a uma mesma etnia como dos Ucranianos, dos Alemães, e comunidades de etnias diversas. A Igreja pode se constituir num indicativo, para se identificar à etnia que detém hegemonia cultural.

Se tomarmos as tradições ou as manifestações culturais como indicativos da preservação e da manutenção de uma certa cultura, verificaremos que a cultura cabocla está dando lugar a uma outra, de difícil qualificação.

Nas comunidades de miscigeFAMILIAR ENTRE OS NOVOS DESA. FIOS DO MUNDO MODERNO 
nação cultural, a Dança de São Gonçalo desaparece, não há hegemonia do caboclo, mas também não se pode dizer que o caboclo assimilou as práticas ucranianas, ou alemãs, ou outras. Em certo sentido, há um certo ajustamento cultural, onde o alemão já é mais caboclo e o caboclo talvez mais próximo dos padrões da sociedade em geral. É na perspectiva de um certo "acaboclamento", que muitos se situam quando indagados sobre a sua origem étnica. Embora possam lembrar que pais ou avós falassem alemão ou outra língua estrangeira, dizem-se caboclos, por que se identificam na forma de se expressar, através da fala, do modo de vestir, de construir suas casas. Nestas condições, há uma certa descaracterização cultural, e tanto a cultura do caboclo, quanto a do imigrante dá lugar a um certo modo de ser próprio do campônio de modo geral, que os identifica por um lado, mas que por outro, reflete a assimilação de um padrão cada vez mais urbano. Este lado é demonstrado principalmente pelos jovens que ao freqüentarem escolas urbanas, ou assimilando um padrão televisivo dificilmente se distingue de um jovem que vive na cidade.

Este ajustamento cultural, já demonstrado claramente em relação ao caipira de Bofete (CANDIDO: 1975), no entanto, não significa desintegração da vida comunitária, em praticamente $84 \%$, dos entrevistados RURE$\mathrm{CO}$, considerando que $16 \%$ dos entrevistados convivem com apenas uma instituição, conforme a tabela 14. Para os agricultores que compartilham o espaço das organizações comunitárias, as práticas culturais que se realizam na comunidade reforçam valores do grupo, e preservam uma rede de relações face à face que os distingue do mundo exterior (MENDRAS: 1978). As atividades comunitárias, nesse sentido, valorizam positivamente a solidariedade, criam novas formas de integração (como a troca de dias, aquisição conjunta de mercadorias), fortalecem as instituições que os promovem e reforçam a identidade de grupo.

\subsection{Associações e Cooperativas}

A participação em cooperativas, que constitui uma prática solidária de realização econômica, dáse através de índices menores, $50 \%$ e $48 \%$, mas igualmente equilibrados entre os da rede RURECO e outros agricultores

Observa-se na tabela 15 que as organizações com objetivo semelhantes, as Associações Comerciais, tem uma participação mais intensa dos agricultores da rede RURECO: $92 \%$. Ocorre que essas associações foram organizadas por esses agricultores e se localizam na sede dos municípios; daí a explicação da participação intensa desse grupo de produtores em cargos de direção. Elas se distinguem das cooperativas pela fato de não comercializar a produção mas apenas realizar compra de mercadorias para o consumo dos agricultores.

\subsection{Sindicatos e partidos políti-} $\cos$

O grau de participação em instituições de natureza política, como sindicatos e partidos políticos, revela uma acentuada mobilização política dos entrevistados, principalmente os agricultores da rede RURECO. 70\% destes agricultores são sindicalizados e $50 \%$ são filiados a partidos políticos. Este índice pode ser considerado expressivo para os agricultores da região, mesmo para aqueles fora da rede (48\% e $22 \%$ ), considerando que classicamente a sociologia sempre considerou o camponês como uma classe conservadora sob o ponto de vista político.

O conservadorismo do camponês, contudo, pode ser questionado dependendo do ponto de vista que se coloca. Se tomarmos como uma classe qualitativamente distinta, mas amorfa e subalterna aos interesses dominantes que desaparece com o desenvolvimento do capitalismo industrial, o camponês sem projetos políticos simplesmente não existe historicamente. Por outro lado, se o tomarmos em sua unidade microssocial e analisarmos a capacidade de ajustamento da forma familiar de produzir, verificaremos que demonstram uma estabilidade excepcional em todo o mundo (SHANIN: 1979). Enquanto categoria que prioriza as relações familiares, e que tem no parentesco fator de amortecedor de conflitos, os camponeses têm-se 
demonstrado conservadores, acrescidos das características da passividade e da subalternatividade (SHANIN: 1979). Mas, a estratégia adotada pelos camponeses, de construir projetos a nível microssocial a partir de interesses imediatos, de resistirem a determinadas mudanças e de se demonstrarem indiferentes em dada conjuntura político econômica, os tem beneficiado praticamente (HOBSBAWN; sd.) É preciso considerar que, modernamente, não é pelo fato do camponês de ontem não apresentar projetos políticos para a sociedade de modo geral, que o agricultor familiar de hoje não elabore o seu projeto, e não construa a sua utopia. Esta, através da reafirmação constante da sua organização - a comunitária -, parece constituir uma das suas razões de ser e de existir. Os projetos camponeses, como a bibliografia tem demonstrado, pelo seu caráter fragmentado e pela diversidade de sua condição (SHANIN; 1979) não possuem uma articulação entre si, mas nem por isso deixam de se constituir como sendo projetos de seu interesse. É a partir desta ótica, da ótica dos interesses dos participantes dos movimentos sociais e da conjuntura social que os orientam, que modernamente apontam análises na sociologia (PRZEWORSKI: 1989). Nesse sentido, a tarefa dos intelectuais consistiria em auxiliar os trabalhadores, nos movimentos de construção e de realização de seus projetos, e não apenas criticá-los. Como bem afirma Touraine, sua própria expressão, "os intelectuais deveriam ajudar os trabalhadores a se transformarem em sujeitos" (TOURAINE: 1992).

Os agricultores da região assessorados pela RURECO, a partir da organização comunitária, fizeram surgir movimentos como, dos jovens agricultores, das mulheres, dos posseiros. Entre estes o que mais repercute na região é certamente o movimento dos posseiros, dada a sua relação direta com a sobrevivência dos agricultores. Este movimento, pela sua importância, confunde-se com o surgimento da Associação dos Agricultores de Pinhão, que por demanda dos posseiros os organiza politicamente no sentido de reivindicar seus direitos.

\section{6-A Agricultura Familiar Alternativa}

A análise realizada demonstra que os agricultores orientados pela RURECO se distinguem dos OUTROS, principalmente em razão de praticar a agricultura mediante o uso da força de tração animal e de sistemas alternativos de cultivo. Esta forma de produzir, alternativa ao padrão agroquímico ou industrial, é definida pelo uso e manejo de recursos naturais conjugado com outros padrões técnicos de cultivo. Não é portanto uma agricultura oposta ao padrão industrial, mas uma agricultura que procura potencializar os recursos internos da propriedade e reduzir o uso de insumos agroquímicos.
Sob o ponto de vista da organização social e política, os agricultores da rede RURECO se destacam na participação de organizações sindicais e partidos políticos.

As dimensões (relacionadas com a produção e com a organização social e política) analisadas parecem fortalecer a mobilização dos agricultores não apenas para se realizarem economicamente mas para se tornarem sujeitos sociais.

\section{7 - Bibliografia Citada}

BRANDENBURG, Alfio e FERREIRA, Angela. Da agricultura familiar contratualizada à agroindústria. Seminário: Inovações tecnológicas e reestruturação do sistema alimentar. Curitiba: UFPR, 1991.

CANDIDO, Antônio. Os parceiros do Rio Bonito. $3^{\text {a }}$.ed. São Paulo: Livraria Duas Cidades, 1975.

FRANCO, Maria Sylvia Pantoja. Xagú: de sem-terra a assentado. Rio de Janeiro: UFRJ, 1992 (dissertação de mestrado)

HOBSBAWM, Eric. Os caponeses e a política. Ensaios de opinião. s.d.

LAGRAVE, R.M. Diversité et reproduction des exploitations. In: JOLLIVET, Marcel. Pour une agriculture diversifiée. Paris: L'Harmattan, 1988.

KAGEYAMA, Angela. O novo padrão agrícola brasileiro: do complexo rural aos complexos agroindustriais. In: DELGADO, Guilherme Costa. Capital financeiro e agricultura no Brasil. São 


\section{Alfio Brandenburg}

Paulo: Ícone/UNICAMP, 1985.

MENDRAS, Henry. Sociedades Camponesas. Rio de Janeiro: Zahar, 1978.

NEVES, Delma Pessanha. Lavradores e pequenos produtores de cana. Rio de Janeiro: Zahar, 1981.

PAULILO, Maria Ignez Silveira. Produtor e Agroindústria: consensos e dissensos. Florianópolis: UFSC, 1990.

PRZEWORSKI, Adam. Capitalismo e social-democracia. São Paulo: Companhia das Letras, 1989.

QUEIRÓZ, Maria Isaura P. O campesinato brasileiro. São Paulo: Vozes, Edusp, 1973.

SANTOS, José Vicente Tavares. Colonos do Vinho. São Paulo: Hucitec, 1978.

SHANIN, Teodor. El campesinato como factor político. In: SHANIN, Teodor. Campesinos y sociedade campesinas. México: Fundo de Cultura Econômica, 1979.

TOURAINE, Alain. Critique de la modernité. Paris: Fayard, 1992.

WANDERLEY, Maria de Nazareth Baudel. Trajetória social e projeto de autonomia: os produtores familiares de algodão da região de Campinas, São Paulo. Cadernos IFCH/UNICAMP. Campinas: Unicamp, $\mathrm{n}^{\circ} .19$, 1989.

WESTHALEN, Maria Cecília; MACHADO, Brasil Pinheiro; BALHANA, Altiva Pilati. Nota prévia ao estudo da ocupação da terra no Paraná moderno. Boletim da Universidade Federal do Paraná/Departamento de História. Curitiba: nº.7, 1968.

FIOS DO MUNDO 